\title{
Vasomotor responses to the Valsalva manoeuvre in normal subjects and in patients with diabetes mellitus
}

\author{
T. BENNETT, D. J. HOSKING, AND J. R. HAMPTON \\ From the Department of Physiology and Pharmacology, University Hospital and Medical School; and \\ Department of Medicine, General Hospital, Nottingham
}

SUMMARY Cardiovascular responses to the Valsalva manoeuvre were examined in 19 non-diabetic subjects and 32 diabetic patients, some with signs of autonomic dysfunction. All the non-diabetic subjects showed an overshoot in systemic arterial pressure and a bradycardia after the manoeuvre, and in 11 of them only forearm vasoconstriction occurred. However, in eight non-diabetic subjects a forearm vasodilatation was observed at some stage after the Valsalva manoeuvre. Similar patterns of vasomotor responses were seen in some of the diabetic patients. However, those diabetics with postural hypotension showed a systemic arterial hypotension after the Valsalva manoeuvre with no significant change in forearm vascular resistance. Such a response is abnormal but forearm vasodilatation alone may not be.

The Valsalva manoeuvre is routinely used as a means of testing the integrity of cardiovascular reflexes, but the majority of studies have been concerned only with the changes in systemic arterial blood pressure and heart rate evoked by the manoeuvre. Those investigators who have measured forearm blood flow (Sharpey-Schafer, 1953; Roddie et al., 1958; Graf, 1965; Delius et al., 1972) have all reported forearm vasoconstriction after the manoeuvre in normal subjects. The occurrence of a dilatation of the forearm vasculature after the Valsalva manoeuvre has been reported in subjects with autonomic dysfunction (Abboud and Eckstein, 1966; Kontos et al., 1976). In view of the paucity of information about the patterns of vasomotor responses evoked by the Valsalva manoeuvre, we have investigated these in a group of normal subjects, and have compared them with those seen in a group of diabetic subjects, some of whom had evidence of autonomic neuropathy affecting the cardiovascular system.

\section{Subjects and methods}

All subjects gave their informed consent to the study which had been approved by the ethical committee. Nineteen normal men aged 18 to 56 years took part in the investigations. They were free of any cardiovascular abnormalities and were not taking any medication. Thirty-two ( 25 men, 7 women) diabetic Received for publication 28 February 1979 patients aged 21 to 64 years were studied. Details of the normal subjects and diabetic patients are given in Table 1, broken down into the groups into which they fell physiologically (see Results).

All studies were carried out between 1400 and 1600 hours in a temperature controlled laboratory set at $22^{\circ} \mathrm{C}$. Subjects had only a light snack before attending the laboratory and all insulin-treated patients had had their last injection of insulin at least 6 hours previously. At the time of investigation the diabetes in all patients was well controlled. Before any measurements were made each subject lay quietly on a couch for at least 30 minutes. During this time electrocardiograph electrodes were attached to the chest to provide the input to an instantaneous ratemeter (Devices Ltd.), and a mercury-in-silastic strain gauge was applied to the right forearm to measure blood flow by venous occlusion plethysmography (Greenfield et al., 1963). Arterial blood pressure was measured by auscultation in the left arm. (Systolic and diastolic blood pressures were measured to the nearest $2 \mathrm{mmHg}$. While these measurements were made as precisely as possible, their accuracy depends upon the relation between the true intra-arterial pressures and the pressures measured by auscultation (King, 1967); this relation is not a simple one. King (1967) has reported that indirect measurement of arterial blood pressure, on average, underestimates systolic blood pressure by $4.4 \mathrm{mmHg}$ and overestimates diastolic blood pressure by $12.6 \mathrm{mmHg}$. However, in our 
experiments the same observer measured the arterial blood pressures in all subjects, thus it is unlikely that random variations in the accuracy of arterial blood pressure measurements could account for systematic differences in calculated forearm vascular resistances.)
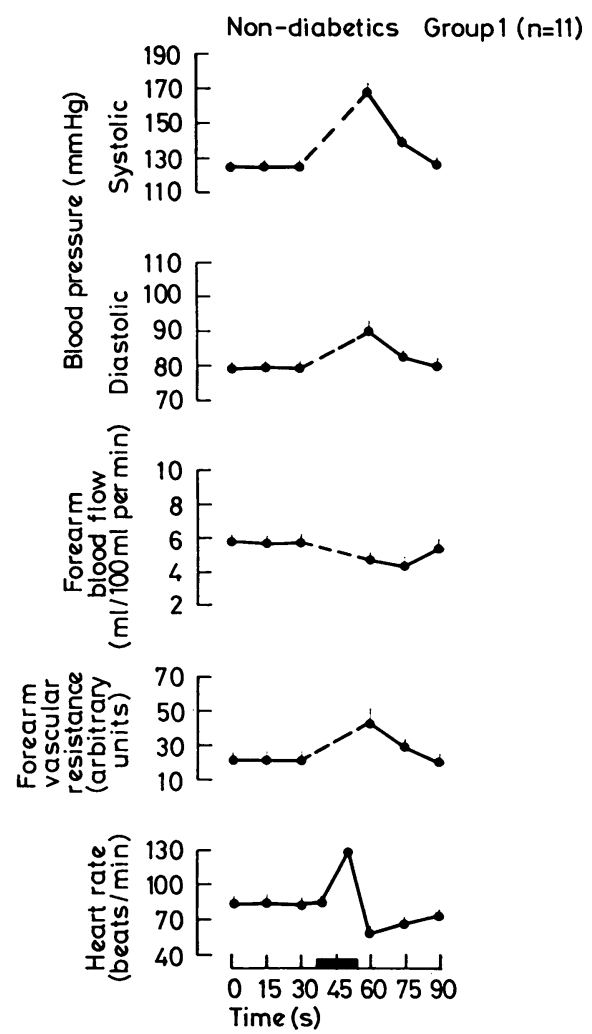

Fig. 1 Cardiovascular responses to a 15-second Valsalva manoeuvre in 11 non-diabetic subjects (group 1). Forearm vascular resistance was significantly $(P<0.001)$ raised after the manoeuvre (from $21 \cdot 3 \pm 4 \cdot 0$ units to $42 \cdot 5 \pm 11 \cdot 0$ units) and gradually fell to the control level.

It was possible to measure heart rate continuously and to obtain simultaneous values of forearm blood flow and brachial arterial blood pressure every 15 seconds. Mean brachial arterial blood pressure ([systolic pressure +2 (diastolic pressure)]/3) was divided by forearm blood flow to give a measure of forearm vascular resistance. Measurements were made until all variables were steady, and the subject was then asked to perform a Valsalva manoeuvre by blowing a mercury column to a height of $40 \mathrm{~mm}$ for 15 seconds. The manometer mouthpiece had a side-arm leak in it to ensure that intrathoracic pressure was persistently raised throughout the manoeuvre. Since meaningful measurements of blood flow could not be made during the manoeuvre, no estimates of forearm vascular resistance could be made during that period. However, measurements of forearm blood flow and systemic arterial blood pressure were made within the 10 second period after the end of the Valsalva manoeuvre, and at 15 second intervals thereafter.

Results were analysed by Student's paired or unpaired $t$ test, as appropriate. Values given in the text are means \pm SEM.

\section{Results}

Before a full analysis of the results, it was clear that the normal subjects and the diabetic patients fell into three corresponding groups, together with a fourth group of diabetic patients who were obviously different from all others. The results are considered in these physiological groupings.

NON-DIABETIC SUBJECTS

All non-diabetic subjects showed a transient overshoot in systemic arterial pressure and a bradycardia after the Valsalva manoeuvre. However, when patterns of change in forearm vascular resistance were considered, the subjects fell into three groups. Eleven subjects (group 1) had a raised forearm vascular resistance after the manoeuvre and this gradually fell towards baseline levels over the next 30 to 40 seconds (Fig. 1). Four subjects (group 2) initially showed a forearm vasoconstriction which reversed to a forearm vasodilatation, though these changes were not statistically significant (Fig. 2). In the remaining four subjects (group 3) forearm vascular resistance was initially reduced and gradually rose to control levels (Fig. 3).

Because of the small numbers of subjects in groups 2 and 3, possible differences between the control values of the variables measured for the separate groups were not analysed statistically. However, a comparison of those subjects who showed no vasodilatation (group 1) with those who showed a fall in forearm vascular resistance at some stage after the Valsalva manoeuvre (groups 2 and 3 ) indicated that, though their resting systolic arterial blood pressures were not significantly different (group $1=126.5 \pm 4.0 \mathrm{mmHg}$; groups 2 and $3=120$ $\pm 3.5 \mathrm{mmHg})$, they did show a significant $(P<0.01)$ difference in systolic arterial pressure after the Valsalva manoeuvre (group $1=171 \cdot 7 \pm 6.0 \mathrm{mmHg}$; groups 2 and $3=146.9 \pm 5 \cdot 0 \mathrm{mmHg}$ ). There was no significant difference between the ages of the subjects in these groups. 
DIABETIC SUBJECTS

Not all diabetic subjects showed hypertension and bradycardia after the Valsalva manoeuvre. However, on the basis of changes in systemic arterial
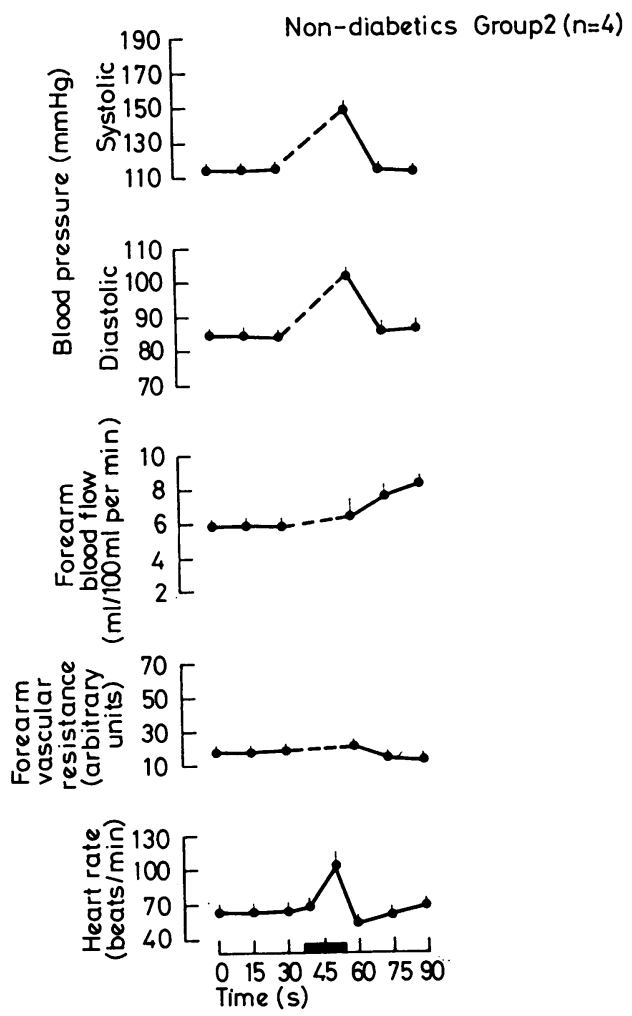

Fig. 2 Cardiovascular responses to a 15-second Valsalva manoeuvre in 4 non-diabetic subjects (group 2). Forearm vascular resistance was raised initially (from $17 \cdot 0 \pm 2 \cdot 0$ units to $20 \cdot 2 \pm 4 \cdot 0$ units) and then fell below control levels (12.2 $\pm 1 \cdot 0$ units) but these changes were not significant, probably because of the small number of subjects.

pressure and forearm vascular resistance, the diabetics fell into four groups. Thirteen subjects (group 1) showed a post-Valsalva overshoot in arterial pressure and a bradycardia; in this group forearm vascular resistance was initially raised and gradually fell to control levels (Fig. 4). Four subjects (group 2) showed a similar pattern of changes in arterial pressure and heart rate, but in these there was a significant forearm constriction followed by a significant forearm vasodilatation (Fig. 5). In group 3 were 10 subjects who showed a post-manoeuvre overshoot in arterial pressure, but only six of these subjects showed a bradycardia (Fig. 6); however, all subjects in group 3 showed a persistent forearm vasodilatation after the manoeuvre. Five subjects (group 4) showed a significant fall in systolic arterial pressure after the manoeuvre, with no significant change in heart rate or forearm vascular resistance (Fig. 7). These patients were those with postural hypotension (Table 1). Under resting conditions the systolic blood pressure of subjects in group 4 $(163.6 \pm 15.0 \mathrm{mmHg})$ was significantly $(\mathrm{P}<0.02)$ higher than that of the other diabetic subjects (groups $1-3 ; 131.3 \pm 4.3 \mathrm{mmHg}$ ) and their forearm vascular resistance was significantly $(P<0.001)$ greater (group $4=54.4 \pm 7.9$; groups $1-3=29.6$ $\pm 3 \cdot 4)$.
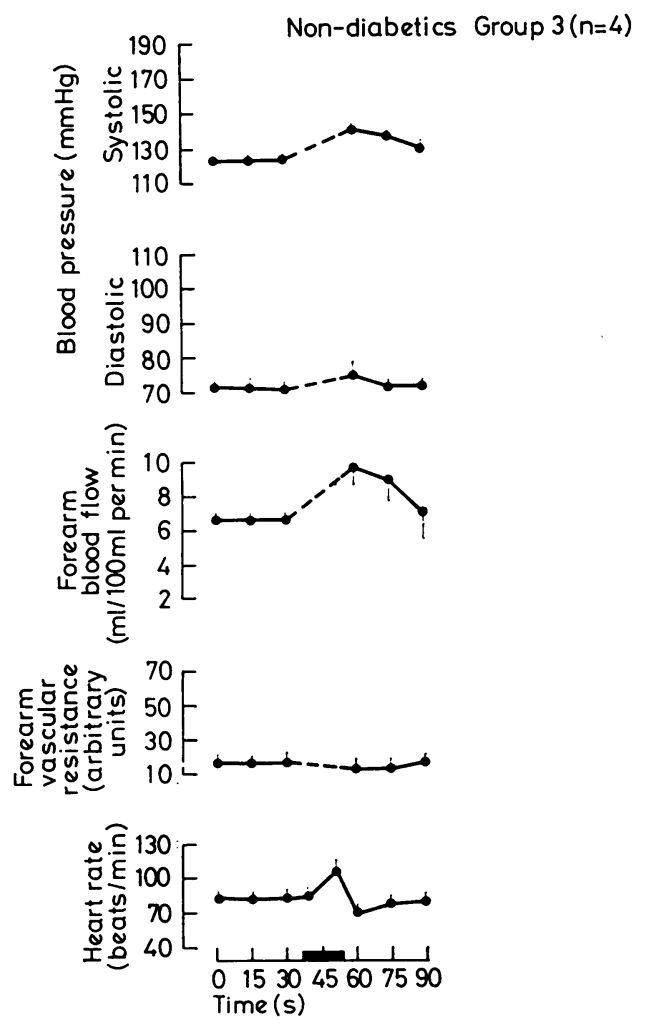

Fig. 3 Cardiovascular responses to a 15-second Valsalva manoeuvre in 4 non-diabetic subjects (group 3). Forearm vascular resistance was significantly $(0.05>P>0.02)$ reduced after the manoeuvre (from $15.7 \pm 3.0$ units to $11.4 \pm 2.0$ units) and gradually rose to control levels.

COMPARISON OF NON-DIABETIC AND DIABETIC SUBJECTS

Excluding diabetics in group 4 who were clearly different from all other groups, there were, none the less, significant differences between the resting levels 
of systolic arterial pressure, forearm vascular resistance, and heart rate in non-diabetics and diabetics (Table 2). There were no consistent differences between the cardiovascular responses to the Valsalva manoeuvre in the non-diabetics and diabetics in the corresponding groups. In some cases the non-diabetics showed the largest changes
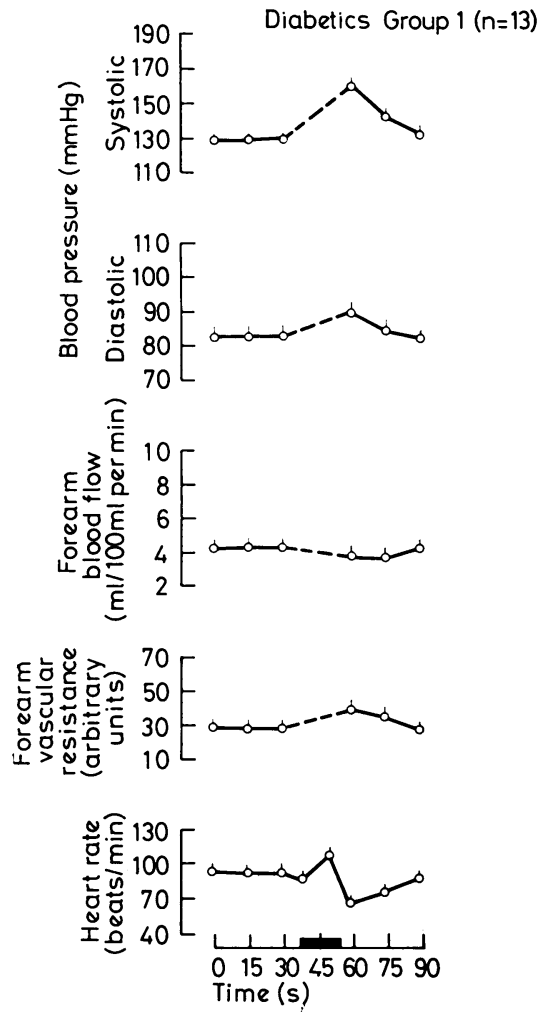

Fig 4 Cardiovascular responses to a 15-second Valsalva manoeuvre in 13 diabetic subjects (group 1). Forearm vascular resistance was significantly $(0.01>P>0.001)$ increased after the manoeuvre (from $27 \cdot 0 \pm 3 \cdot 0$ units to $38 \cdot 0 \pm 4 \cdot 0$ units) and gradually fell towards control levels.

(compare Fig. 1 and 4) while in others the diabetics showed the greatest responses (compare the changes in forearm vascular resistance in Fig. 2 and 5).

\section{Discussion}

Previous studies on the cardiovascular responses to the Valsalva manoeuvre in diabetes have been confined to a consideration of changes in systemic arterial pressure and/or heart rate (Bennett et al., 1976; Ewing, 1978). The problems associated with quantifying the responses on the basis of heart rate changes alone have been commented upon previously (Bennett et al., 1976, 1978), but generally our findings are consistent with previous reports, where they deal with arterial pressure and heart rate changes.

However, the present observations are new and potentially important because they cause one to question traditional thinking about what constitutes a normal Valsalva response.

As mentioned in the introduction, previous studies on forearm vascular resistance changes in
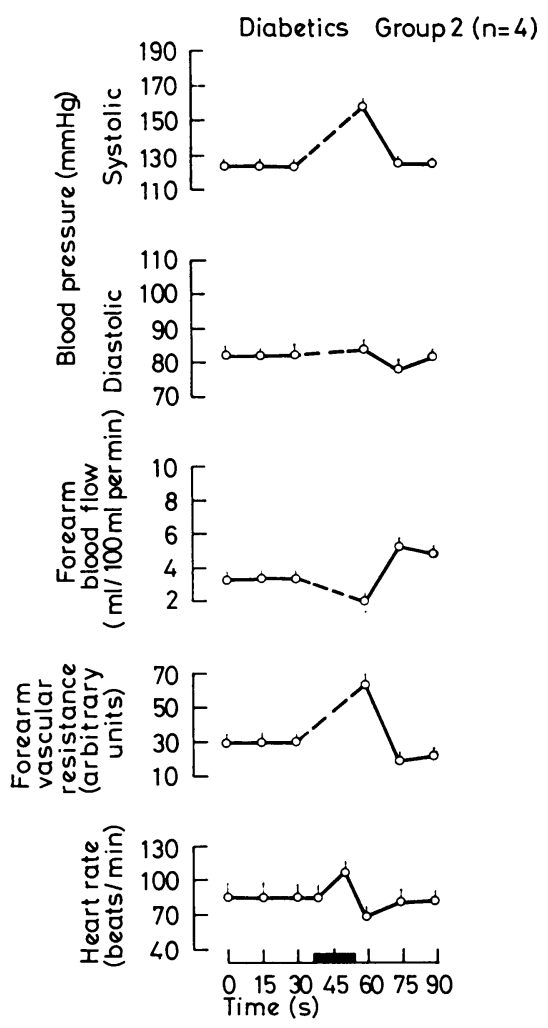

Fig. 5 Cardiovascular responses to a 15-second Valsalva manoeuvre in 4 diabetic subjects (group 2). Initially, forearm vascular resistance was significantly $(P<0.001)$ raised after the manoeuvre (from $29 \cdot 7 \pm 2 \cdot 0$ units to $61 \cdot 0 \pm 6 \cdot 0$ units) but then fell below control levels (to $18 \cdot 6 \pm 1 \cdot 0$ units; $0.05>P>0.02$ ).

normal subjects in response to the Valsalva manoeuvre have indicated that only a vasoconstriction occurs. However, this classical picture is not readily explained by recourse to the underlying physiology. An increase in central blood volume elicits reflex forearm vasodilatation in man (Roddie et al., 1957; 
Brown et al., 1966; Bennett et al., 1979), and after the Valsalva manoeuvre there is an acute increase in central blood volume which would be expected to elicit reflex forearm vasodilatation caused by inhibition of vasoconstrictor tone (Brown et al., 1966).
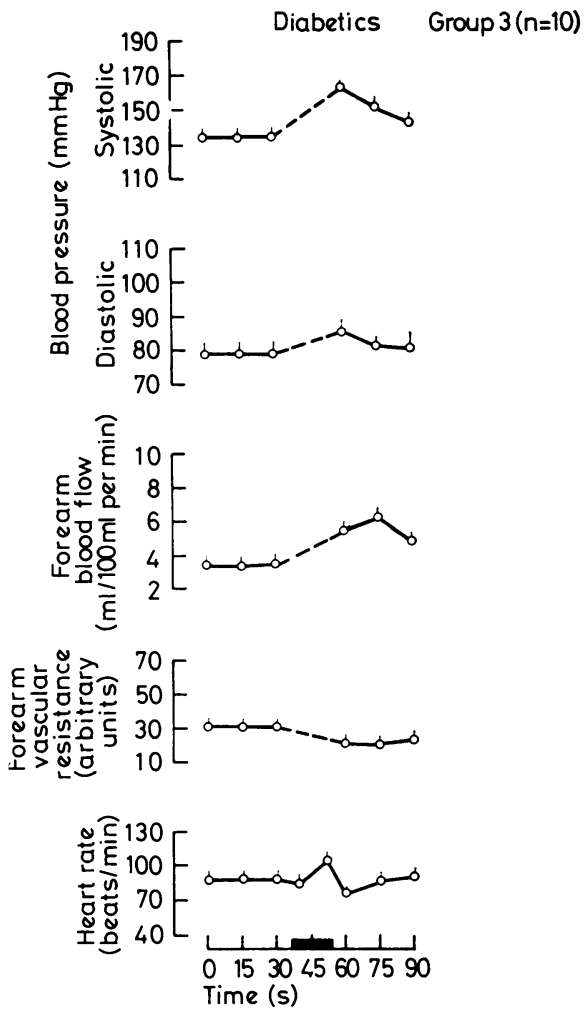

Fig. 6 Cardiovascular responses to a 15-second Valsalva manoeuvre in 10 diabetic subjects (group 3). Forearm vascular resistance was significantly $(0.05>P>0.02)$ reduced after the manoeuvre (from $32 \cdot 2 \pm 6 \cdot 0$ units to $22 \cdot 1 \pm 4 \cdot 0$ units) and remained so for some time. In the figure the mean heart rate shown includes those subjects who showed no bradycardia after the manoeuvre; excluding them the post-Valsalva heart rate was $70 \pm 4$ beats/min.

Delius et al. (1972) estimated forearm vascular resistance and measured action potential discharge in forearm skeletal muscle vasomotor fibres in subjects performing a Valsalva manoeuvre. They found vasomotor nerve fibre discharge was inhibited after the manoeuvre, but vascular resistance remained raised. Delius et al. (1972) suggested that the persistence of the forearm vasoconstriction might be the result of 'inertia' in the process of relaxation after intense vasoconstriction, or that it might be the result of a local myogenic response to the raised arterial pressure. However these suggestions are difficult to reconcile with the observation that prolonged periods of forearm vasoconstriction, elicited by reduction in central blood volume, can be followed by distinct reflex forearm vasodilatation (Brown et al., 1966; Bennett et al., 1979). Furthermore, many of the subjects in the present study who showed a forearm vasoconstriction after the Valsalva manoeuvre none the less showed a pronounced
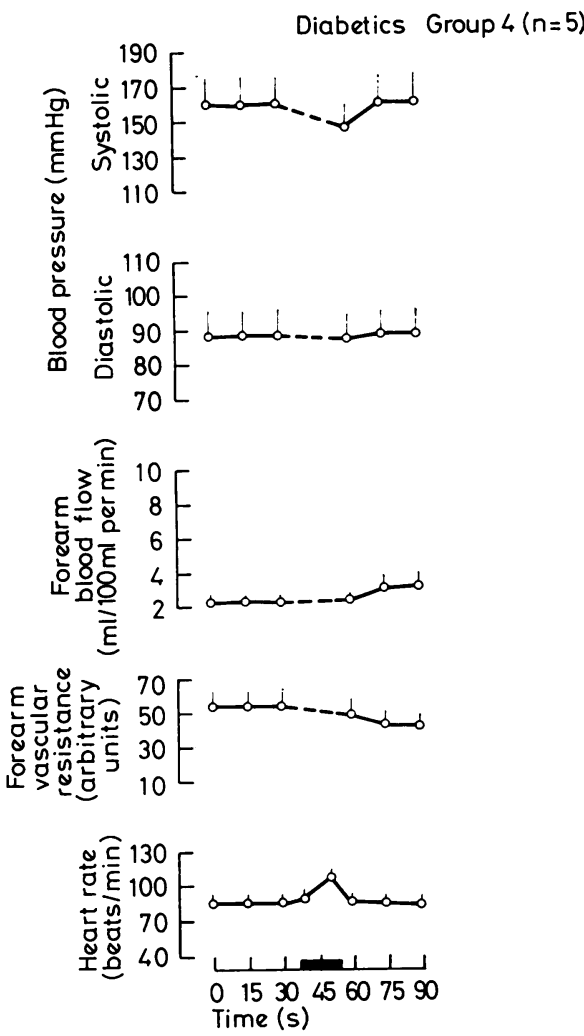

Fig. 7 Cardiovascular responses to a 15-second Valsalva manoeuvre in 5 diabetic subjects (group 4). After the manoeuvre systolic blood pressure was significantly $(P<0.05)$ decreased (from $164 \pm 15.0$ $\mathrm{mmHg}$ to $150 \pm 13.0 \mathrm{mmHg}$ ) and gradually returned to baseline levels. Though the changes in the other measured variables were not significant (probably because of the small size of the group) the pattern of response is clearly different from that of all other groups described.

forearm vasodilatation after lower body negative pressure (Bennett et al., 1979).

Whatever the explanation of the present and previous results, we do not believe that forearm vasodilatation after the Valsalva is of itself an indication of vasomotor abnormality. Such a response was 
Table 1 Details of the normal subjects and diabetic patients studied

\begin{tabular}{|c|c|c|c|c|c|c|c|}
\hline & $\begin{array}{l}\text { Group } 1 \\
\text { Normal }\end{array}$ & Diabetic & $\begin{array}{l}\text { Group } 2 \\
\text { Normal }\end{array}$ & Diabetic & $\begin{array}{l}\text { Group } 3 \\
\text { Normal }\end{array}$ & Diabetic & $\begin{array}{l}\text { Group } 4 \\
\text { Diabetic }\end{array}$ \\
\hline Number of subjects & 11 & 13 & 4 & 4 & 4 & 10 & 5 \\
\hline Sex & $11 \mathrm{M}$ & $12 \mathrm{M}, 1 \mathrm{~F}$ & $4 M$ & $4 M$ & $4 M$ & $8 \mathrm{M}, 2 \mathrm{~F}$ & $1 \mathrm{M}, 4 \mathrm{~F}$ \\
\hline Duration of diabetes, mean and range $(y)$ & - & $9(2-16)$ & - & $10(0.5-15)$ & - & $12(6-20)$ & $19(10-40)$ \\
\hline Treatment: Insulin & - & 8 & - & 4 & - & 7 & 4 \\
\hline Oral hypoglycaemics & - & 5 & - & - & - & 3 & 1 \\
\hline Haemorrhages and exudates & - & 4 & - & - & - & $\overline{1}$ & 1 \\
\hline Proliferative & - & - & - & - & - & 1 & 2 \\
\hline Somatic neuropathy & - & 3 & - & - & - & 4 & 4 \\
\hline Postural hypotension & - & - & - & - & - & - & 5 \\
\hline Abnormal $(<5)$ beat-to-beat variation in heart rate & - & - & - & - & - & 4 & 5 \\
\hline
\end{tabular}

Note that though the corresponding groups of non-diabetic subjects and diabetic patients are fairly well matched for age, the patients in group 4 are, on average, the oldest and have had diabetes longer than the other patients.

seen in 8 out of 19 normal subjects in the present study (considering groups 2 and 3 together). There was no systematic difference between these subjects and those who showed no forearm vasodilatation, except that in the latter the post-Valsalva hypertension was greater and more persistent than in the former, but this would be expected in the absence of reflex skeletal muscle vasodilatation.

The responses of the diabetic subjects in groups 1,2 , and 3 were not consistently different from those of the non-diabetics in the corresponding groups. However, compared with the non-diabetics, a somewhat larger proportion of the diabetics studied showed only forearm vasodilatation after the manoeuvre $(31 \%$ against $21 \%$ ), and of these diabetics (group 3) 4 out of 10 showed no bradycardia in response to systemic arterial hypertension. This latter observation is an indication of autonomic neuropathy, perhaps affecting vagal efferent control of the heart (Bennett et al., 1976), and is consistent with the finding that these 4 subjects had abnormally small beat-to-beat variations in heart rate (Bennett et al., 1975, Table 1). Thus, while occurrence of forearm vasodilatation after the Valsalva manoeuvre is not necessarily a sign of abnormality, it does not follow that it indicates normal autonomic nervous function.

Table 2 Resting cardiovascular variables in non-diabetics (groups 1-3) and diabetics (groups 1-3)

\begin{tabular}{|c|c|c|}
\hline & $\begin{array}{l}\text { Non-diabetics } \\
(n=19)\end{array}$ & $\begin{array}{l}\text { Diabetics } \\
(n=27)\end{array}$ \\
\hline $\begin{array}{l}\text { Systolic blood pressure }(\mathrm{mmHg}) \\
\text { Diastolic blood pressure }(\mathrm{mmHg}) \\
\text { Forearm blood flow }(\mathrm{ml} / 100 \mathrm{ml} \\
\text { per min) }\end{array}$ & $\begin{array}{r}122 \cdot 3 \pm 3 \cdot 6 \\
78 \cdot 5 \pm 3 \cdot 5 \\
6 \cdot 1 \pm 1 \cdot 1\end{array}$ & $\begin{aligned} \star 131 \cdot 3 & \pm 4 \cdot 3 \\
81 \cdot 7 & \pm 3 \cdot 8 \\
\star 3 \cdot 7 & \pm 0 \cdot 3\end{aligned}$ \\
\hline $\begin{array}{l}\text { Forearm vascular resistance } \\
\text { (arbitrary units) }\end{array}$ & $18 \cdot 0 \pm 3 \cdot 0$ & $\star 29.6 \pm 3.4$ \\
\hline Heart rate (beats/min) & $75 \cdot 2 \pm 5 \cdot 2$ & $\star 83.8 \pm 5.0$ \\
\hline
\end{tabular}

There were significant differences between the resting levels of cardiovascular variables in the diabetics and non-diabetics in groups 1 to 3 (Table 2). The moderately raised systolic arterial pressure associated with a slight tachycardia and forearm vasoconstriction could have been the result of anxiety in the patients compared with the volunteer subjects. However, it is also possible that such differences were the result of subclinical cardiovascular disease in the patients (Bennett et al., 1979).

The only diabetic subjects whose vasomotor response to the Valsalva manoeuvre was undoubtedly abnormal were those in whom there was a post-manoeuvre hypotension with no significant bradycardia or increase in forearm vascular resistance (though the mean value of the latter was reduced). This pattern of response is similar to that seen in other subjects with signs of autonomic dysfunction (Abboud and Eckstein, 1966; Kontos et al., 1976), and where arterial blood pressure falls but forearm flow increases we agree that the response is abnormal. However, we found that subjects with this pattern of response may none the less show forearm vasoconstriction in response to lower body negative pressure (Bennett et al., 1979) and thus any subject is best investigated using a variety of manoeuvres in order to build up a meaningful profile of the dysfunction.

The resting cardiovascular status of the diabetics in group 4 was very similar to that of patients with borderline hypertension in whom the raised blood pressure appears to be the result of autonomic nervous hyperactivity (Julius and Esler, 1975). However, the response of the diabetics to the Valsalva manoeuvre indicated that autonomic nervous control of the cardiovascular system was impaired. Since the diabetics in this group were those who showed postural hypotension, it is possible that they had increased blood volumes (caused 
by a renal compensation for the reduction in effective blood volume when upright). A plasma volume expansion could account for the raised systolic blood pressure in the supine position, but it is not clear to what extent this systolic hypertension might have been responsible for the observed abnormalities in cardiovascular control. Eighty per cent of the diabetic patients in group 4 were women, but, on average, they were also older and had had diabetes longer than the patients in the other groups. It is, therefore, impossible from the present results to determine whether or not the abnormalities described are commoner in women.

We are grateful to Professor P. H. Fentem for his constructive criticisms of the manuscript.

\section{References}

Abboud, F. M., and Eckstein, J. W. (1966). Active reflex vasodilatation in man. Federation Proceedings, 25, 16111617.

Bennett, T., Farquhar, I. K., Hosking, D. J., and Hampton, J. R. (1978). Assessment of methods for estimating autonomic nervous control of the heart in patients with diabetes mellitus. Diabetes, 27, 1167-1174.

Bennett, T., Hosking, D. J., and Hampton, J. R. (1975). Cardiovascular control in diabetes mellitus. British Medical Fournal, 2, 585-587.

Bennett, T., Hosking, D. J., and Hampton, J. R. (1976). Baroreflex sensitivity and responses to the Valsalva manoeuvre in subjects with diabetes mellitus. Fournal of Neurology, Neurosurgery and Psychiatry, 39, 178-183.

Bennett, T., Hosking, D. J., and Hampton, J. R. (1979). Cardiovascular responses to lower body negative pressure in normal subjects and in patients with diabetes mellitus. Cardiovascular Research, 13, 31-38.

Brown, E., Goei, J. S., Greenfield, A. D. M., and Plassaras,
G. C. (1966). Circulatory responses to simulated gravitational shifts of blood in man induced by exposure of the body below the iliac crests to sub-atmospheric pressure. Fournal of Physiology, 183, 607-627.

Delius, W., Hagbarth, K-E., Hongell, A., and Wallin, B. G. (1972). Manoeuvres affecting sympathetic outflow in human muscle nerves. Acta Physiologica Scandinavica, 84, 82-94.

Ewing, D. J. (1978). Cardiovascular reflexes and autonomic neuropathy. Clinical Science and Molecular Medicine, 55, 321-327.

Graf, K. (1965). The effects on some reflex stimuli, hypoxia and hypercapnia on the resistance of blood vessels in the forearm and hand of patients with vasoregulatory asthenia. Acta Societatis Medicorum Upsaliensis, 70, 263-278.

Greenfield, A. D. M., Whitney, D. J., and Mowbray, J. F. (1963). Methods for the investigation of peripheral blood flow. British Medical Bulletin, 19, 101-109.

Julius, S., and Esler, M. (1975). Autonomic nervous cardiovascular regulation in borderline hypertension. American Fournal of Cardiology, 36, 685-696.

King, G. E. (1967). Errors in clinical measurement of blood pressure in obesity. Clinical Science, 32, 223-237.

Kontos, H. A., Richardson, D. W., and Norvell, J. E. (1976). Mechanism of circulatory dysfunction in orthostatic hypotension. Transactions of the American Clinical and Climatological Association, 87, 26-34.

Roddie, I. C., Shepherd, J. T., and Whelan, R. F. (1957). Reflex changes in vasoconstrictor tone in human skeletal muscle in response to stimulation of receptors in a lowpressure area of the intrathoracic vascular bed. Fournal of Physiology, 139, 369-376.

Roddie, I. C., Shepherd, J. T., and Whelan, R. F. (1958). Reflex changes in human skeletal muscle blood flow associated with intrathoracic pressure changes. Circulation Research, 6, 232-238.

Sharpey-Schafer, E. P. (1953). Effects of coughing on intrathoracic pressure, arterial pressure and peripheral blood flow. Fournal of Physiology, 122, 351-257.

Requests for reprints to Dr. T. Bennett, Department of Physiology and Pharmacology, Medical School, Queen's Medical Centre, Nottingham NG7 2UH. 